\title{
Erratum to: Functional consequences of a section of the anterior part of the body of the corpus callosum: evidence from an interhemispheric transcallosal approach
}

Johann Peltier • Martine Roussel - Yasmina Gerard •

Maryse Lassonde · Hervé Deramond - Daniel Le Gars •

Louis De Beaumont $\cdot$ Olivier Godefroy

Published online: 12 January 2013

(c) Springer-Verlag Berlin Heidelberg 2013

Erratum to: J Neurol (2012) 259:1860-1867

DOI 10.1007/s00415-012-6421-x

Unfortunately, the family names of Louis De Beaumont and Daniel Le Gars were published wrongly in the original version of the article. The correct family names are De Beaumont and Le Gars.

The online version of the original article can be found under doi:10.1007/s00415-012-6421-x.

J. Peltier · D. Le Gars

Laboratory of Anatomy and Organogenesis,

University of Picardy Jules Verne, Amiens, France

J. Peltier · M. Roussel · Y. Gerard · O. Godefroy

Laboratory of Functional Neurosciences and Pathology UMR

CNRS 8160, University of Picardy Jules Verne, Amiens, France

J. Peltier $(\bowtie)$

Department of Neurosurgery, Amiens University Hospital,

Victor Pauchet Place, 80054 Amiens Cedex 1, France

e-mail: peltier.johann@chu-amiens.fr

M. Roussel · Y. Gerard · O. Godefroy

Department of Neurology,

Amiens University Hospital,

Amiens, France

M. Lassonde · L. De Beaumont

Centre de Recherche en Neuropsychologie et Cognition,

Université de Montreal, Montreal, QC H3C 3J7, Canada

H. Deramond

Department of Neuroradiology,

Amiens University Hospital, Amiens, France 